\title{
Power Scheduling for Renewable Energy Connected to the grid
}

\author{
Ismail El kafazi ${ }^{1}$, Rachid Bannari ${ }^{2}$, Abdellah Lassioui ${ }^{3}$ and My Othman Aboutafail ${ }^{4}$ \\ ${ }^{1,2}$ Laboratory Systems Engineering, Ensa, Ibn Tofail University Kenitra, Morocco; \\ ${ }^{3}$ ESIT Team, LGS Laboratory, Ibn Tofail University Kenitra, Morocco; \\ ${ }^{4}$ Laboratory of Electrical, Engineering Computing Sciences EECOMAS, Ibn Tofail University Kenitra, Morocco.
}

\begin{abstract}
In this work, a scheduling strategy considering an Energy Storage System (ESS) is proposed to manage the distributed energy resources (DERs) optimally in a grid-connected hybrid PV-wind- microgrid. In order to increase the use of the renewable energy sources and ensure a full charge in the battery for the next day. The optimization problem of this study is addressed through a linear mathematical model, to minimize the cost of energy bought from the utility grid and maximize the income for selling electricity generated by hybrid PV-wind. The optimization model is tested by using a simulation of the model. The achieved results confirm the effectiveness of the proposed scheduling strategy.
\end{abstract}

\section{Introduction}

Renewable energy such as Wind Turbine (WT) and Solar energy are the current trend in microgrids (MG). Moreover, Energy Storage Systems (ESSs) supply energy support and provides store energy during times of high generation. An MG has two modes of operation; an islanded mode or connected to the main grid [1]. The ESS coordinates with the RESs and loads in order to avoid excessive charge or discharge which may affect the performance and life-span of the ESS. Furthermore, an Energy Management System (EMS) with the operational conditions of the $\mathrm{MG}$, can define proper operating conditions for the DG based on renewable energy sources (RESs) and loads, looking for an optimal dispatch and commitment between distributed units which ensures reliable operation of the MG regarding specific objectives and generation capacity [2], [3].

Energy management system (EMS) in microgrids is formulated as a nonlinear optimization problem. Diverse methods have been proposed to solve it in the literature, including particle swarm optimization [4], neural networks [5], mixed integer programming [6], and sequential quadratic programming [7].

This paper proposes an EMS to minimize the cost of buying energy from the main grid and maximize the revenue due to the renewables (photovoltaic (PV) energy generation and wind turbine (WT)) while preserving the lifetime of the ESS based on batteries by avoiding overcharge, excessive discharge, and discharge cycles. Additionally, assuring periods of full charge of the ESS, within cycles of discharge based on a $24-\mathrm{h}$ ahead optimal scheduling.

In this proposal, the problem is modeled as a mixed integer linear programming (MILP) for scheduling the power of the distributed energy resources. The proposed optimization model is implemented under commercial optimization software such as GAMS.

\section{Operation of the Microgrid}

The microgrid is composed by $10 \mathrm{PV}$ generators with a capacity of $2.4 \mathrm{KW}$ and 1 wind turbine with a capacity of $1 \mathrm{KW}$ as shown in Fig.2. The EMS schedules the generators in interactive and non-interactive way since their power generation may be curtailed from the EMS [8].

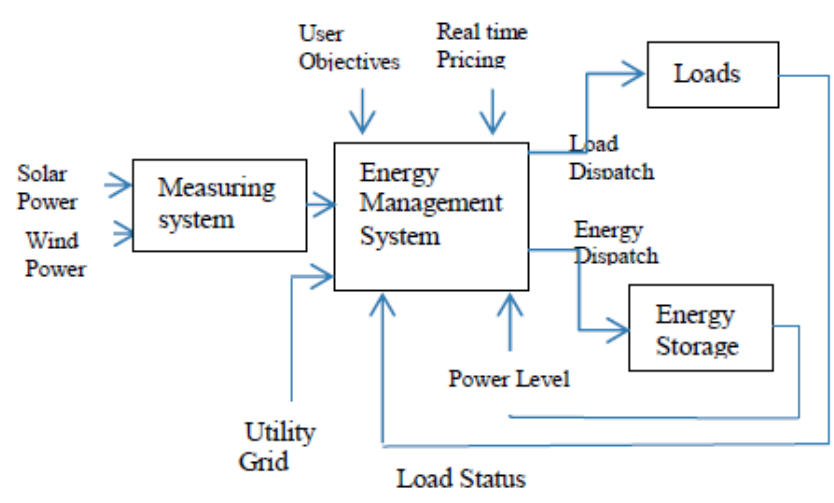

Fig.1. Scheme of the microgrid.

Furthermore, to improve the performance of the ESS a two-level steps which avoid battery overcharge is recommended by the manufacturers. 


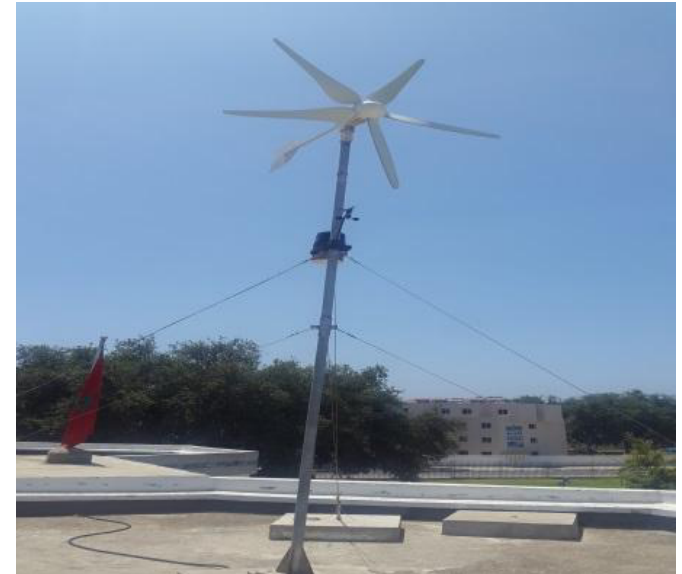

(a)

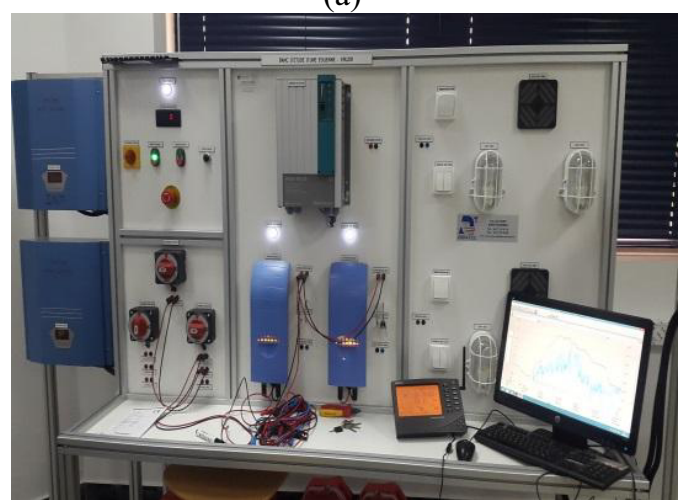

(b)

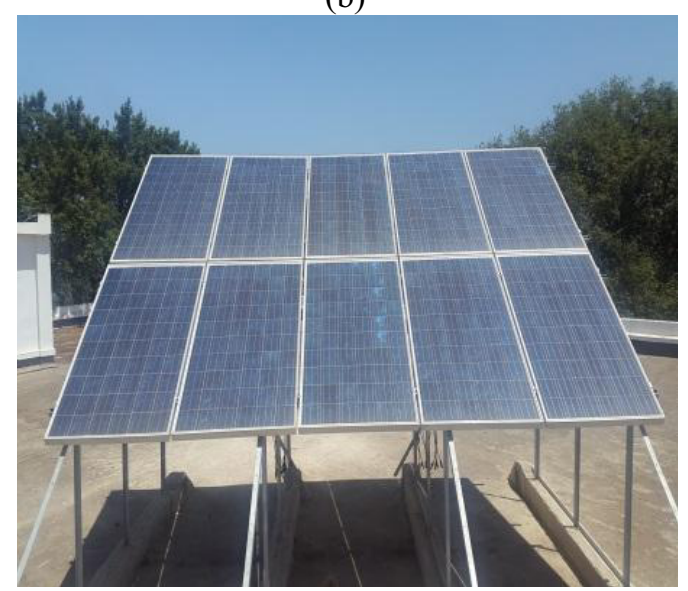

(c)

Fig. 2. Microgrid site in Morocco.

Another thing to avoid excessive discharge of the battery, the state of charge (SoC) of the battery is restricted to $20 \%$ for ensuring a larger lifetime of the battery array $[9,10]$. In this reason, to implement this objective the EMS should ensure proper scheduling of the other distributed energy resources including the main grid to get an optimal commitment between battery charge and the energy bought from the network. Additionally, the EMS minimizes the operation of the system to reduce the number of discharge cycles. Apart from that, EMS schedules the operation of the distributed energy resources complementing the microgrid [2]. The proposed EMS has been composed as a modular architecture in which each module performs different functions independently and exchanges information, as can be seen in Fig. 1.

\section{Optimization Model}

The optimization model has been developed as Mixed Integer Linear Programming (MILP) for minimizing the cost of buying energy from the utility grid, maximizing energy efficiency by using ESS and maximizes the revenue obtained by selling power generating by renewable energy.

The parameters and variables used in this model are described in table II. All the generators are assumed to be connected to the grid supplying the total system demand. Therefore the network, losses and load ramp constraints are not taken into account. The model proposed in this paper simultaneously solves the optimization problems of minimizing the cost of buying energy and economic scheduling. Renewables such as PVs and WTs, their output power is dependent on the availability of the primary sources (i.e., solar irradiance or wind). Therefore, the forecast is required to consider them in the energy management optimization as mentioned in Fig.1. Forecasting methods for PV and WT can be used [11-13]. In our proposal model, we assume that the power of a renewable energy beyond the production scheduling is given and there is no operation cost for renewables.

\subsection{Collecting Data}

The first step in this study is collecting data. Data was collected using Vantage Pro 2 Weather Station [14]. The input data assessed for one day (24h) to be used in order to test the system presented in Figure 3.

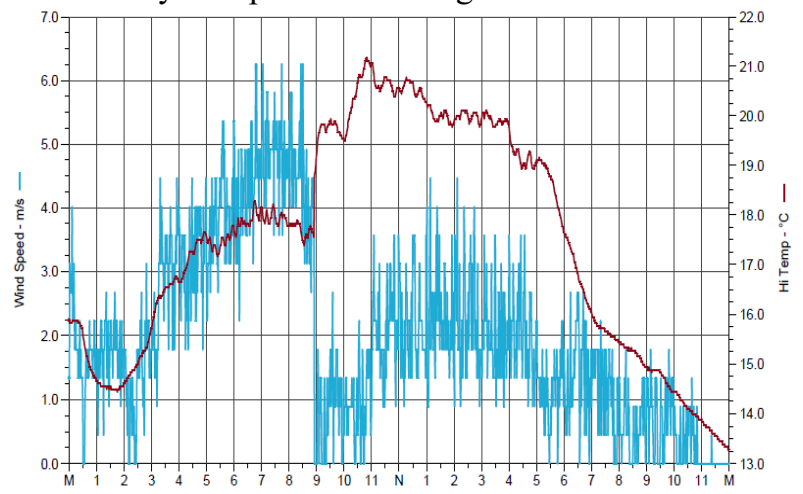

Fig. 3. Hourly wind speed $(\mathrm{m} / \mathrm{s})$ and temperature $(\mathrm{C})$ for one day.

The proposed scheduling strategy enables to determine the quantity of energy required and the amount of energy which need to produce by the available powers. The load demand is an input; we analyze the availability of renewable energy. If this energy is equal or superior to demand we can just use it only whether to transport, sell or storage. On the opposite, if the energy is inferior to the load demand, we need to buy the energy from the utility grid. 


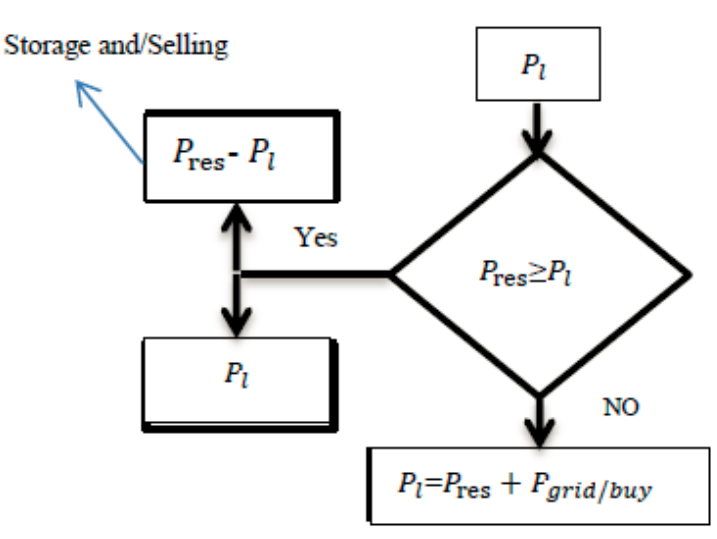

Fig.4. Proposed scheduling strategy.

Table1. Distribution energy per period in the day (24h).

\begin{tabular}{|c|c|c|c|}
\hline Period (t) & $00: 00-08: 00$ & $08: 00-18: 00$ & $20: 00-00: 00$ \\
\hline $\begin{array}{c}\text { Energy } \\
\text { product }\end{array}$ & $\begin{array}{c}P_{\text {res }} \\
\text { Sell energy to } \\
\text { grid }\end{array}$ & $\begin{array}{c}P_{\text {grid }}+P_{\text {res }} \\
\text { Buy energy from } \\
\text { grid }\end{array}$ & $\begin{array}{c}P_{\text {res }} \\
\text { Sell energy to } \\
\text { grid }\end{array}$ \\
\hline
\end{tabular}

Table I provides deciding the primary source of energy used for all the periods in the day. The scheduling from a power supply to the other one is performed at the time of the necessary. Additionally, the table facilitates calculating the production cost every time $\mathrm{t}$.

\subsection{Modeling}

The production operational planning consists in taking decisions to optimally schedule internal production by renewable energy, to cover the local demand, and minimize the cost of imported electricity from the utility grid in the next hours or day. The index $t$ is the elementary unit of time, $t=1,2,3 \ldots$ T. Moreover, the indexes $\mathrm{i}$ is used to represent renewable generators. The objective function has been described as follow:

$$
\begin{gathered}
\mathrm{OF}=\sum_{t=1}^{T}\left(P_{\text {sell }}^{\text {grid }}(t) * C_{\text {sell }}^{\text {grid }}(t)-P_{\text {buy }}^{\text {grid }}(t)\right. \\
\left.* C_{\text {buy }}^{\text {grid }}(t)\right)
\end{gathered}
$$

This objective function (1) aims to minimize the cost of buying energy from the utility grid and maximizing the revenue obtained by generating energy from the RESs. The two terms satisfies the requirements of the optimization problem for the time horizon. Additionally, are related to the energy absorbed from the grid and injected to the grid respectively.

\section{Constraint}

Energy balance (2) is the first condition that the model should include between generation, storage systems and demand in the microgrid.

$$
\begin{gathered}
\sum_{t=1}^{T}\left(P_{\text {sell }}^{\text {grid }}(t)-P_{\text {buy }}^{\text {grid }}(t)\right)+\sum_{i=1}^{2} \lambda_{\text {grid }}(t) * P_{\text {res }, i}(t) \\
+P_{\text {bat }}(t) \stackrel{=}{=} P_{l}(t)
\end{gathered}
$$

The first two terms are related to the energy absorbed from the grid and injected into the grid respectively. In turns, the third expression is the energy provided by the renewables. The variable $\lambda_{\text {grid }}(t)$ enables to manage the energy by sending ON/OFF controls. The last term corresponds to the energy of the battery, to complete the balance, the energy required by the load has to equal to the addition of the previous expressions. Moreover, the boundaries related to the output of the renewable energy are defined as follow:

$$
0 \leq P_{\text {res }, i}(t) \leq P_{\text {res }, i}^{\max }(t) \longleftrightarrow \quad P_{\text {res }}=P_{p v}+P_{w}
$$

The constraints of the utility grid are also described as follow:

$$
\begin{aligned}
& 0 \leq P_{\text {sell }}^{\text {grid }} \leq \sum_{i=1}^{2} \lambda_{\text {grid }}(t) * P_{\text {res }, i}^{\max }(t) \\
& 0 \leq P_{\text {buy }}^{\text {grid }} \leq\left(1-\lambda_{\text {grid }}(t)\right) * P_{\text {max }}^{\text {grid }}(t)
\end{aligned}
$$

In addition, the constraints related to the ESS are defined as follow:

$$
\begin{aligned}
& \left(1-B_{t}\right)+B_{t}=1 \quad \forall t \in T \\
& 0 \leq P_{c h, t}^{\text {bat }} \leq B_{t} * P_{\text {ch.max }, t}^{\text {bat }} \quad B_{t} \in\{0,1\} \forall t \in T \\
& 0 \leq P_{\text {dis }, t}^{\text {bat }} \leq\left(1-B_{t}\right)^{*} P_{\text {dis.max }, t}^{\text {bat }} \quad B_{t} \in\{0,1\} \forall t \in T \\
& E S_{t}^{\text {bat }}=E S_{t-1}^{\text {bat }}+P_{\text {ch,t }}^{\text {bat }} * \eta^{\text {bat }, c h}-P_{\text {dis }, t}^{\text {bat }} / \eta^{\text {bat,dis }} \\
& E S_{\text {min }}^{\text {bat }} \leq E S_{t}^{\text {bat }} \leq E S_{\text {max }}^{\text {bat }} \\
& E S_{t=0}^{\text {bat }}=E S_{t=24}^{\text {bat }}
\end{aligned}
$$

\section{Results}

The scheduling process is executed by applying real data of wind speed and solar irradiance of a summer day. The input data of the obtained RES energy are presented in Fig. 3.

The optimization problem is solved by using the software GAMS as algebraic model language and the solver CPLEX is used in order to compute the power references obtained for the proposed model. The system is implemented to minimize the cost of buying energy from the utility grid and to generate the charging and discharging schedule of the battery.

\subsection{Scheduling Results}

The optimization is solved in order to prove the effectiveness of the objective function. The parameters used in the model are presented in Table II as well as the generation profiles of a summer day with renewable energy generation (Wind and PV) (Fig. 5 and Fig. 6). 


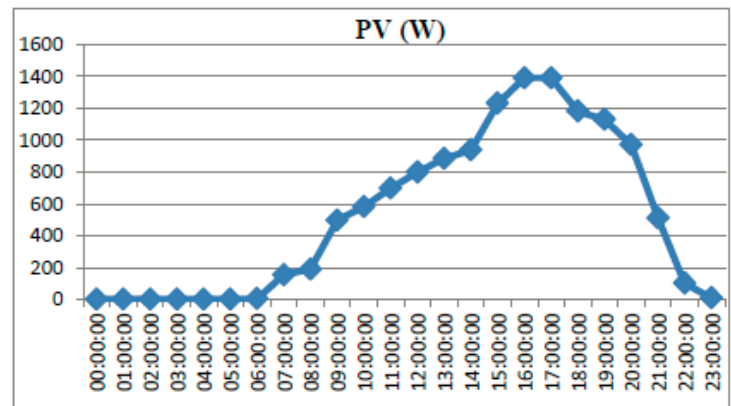

Fig. 5. Energy production from solar energy for one day.

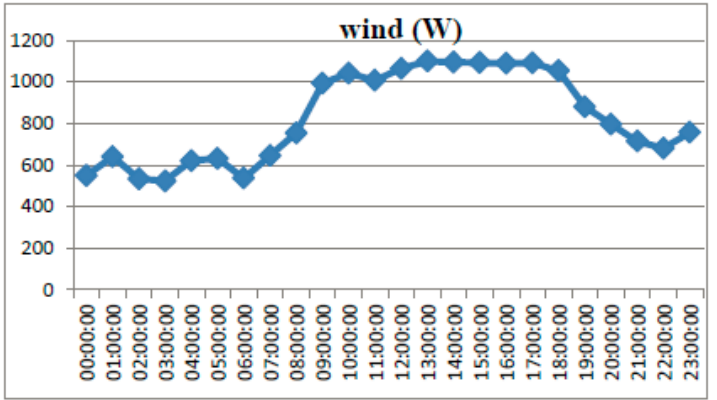

Fig. 6. Energy production from wind energy for one day.

As can be seen, there are a surplus of energy during the day and just part of the energy is employed while some reduction is used. Furthermore, the power profile exchanged with the grid is presented. In this case, the profile is positive when microgrid injects power into the grid (sells) and negative when absorbs power (buys).

On the opposite, the profiles of selling and buying power to the utility are shown in Fig. 7. It is possible to see in Fig. 7 that the surplus of RES energy is sold to the utility where the local generation is enough to supply the load and thus, it is not needed to buy energy from the grid. In addition, from $08 \mathrm{~h}$ the part of the energy generated by wind energy is used in the local consumption and, at the same time, it is required to buy energy from the utility because the energy provided by the PV is not enough to supply the demand.

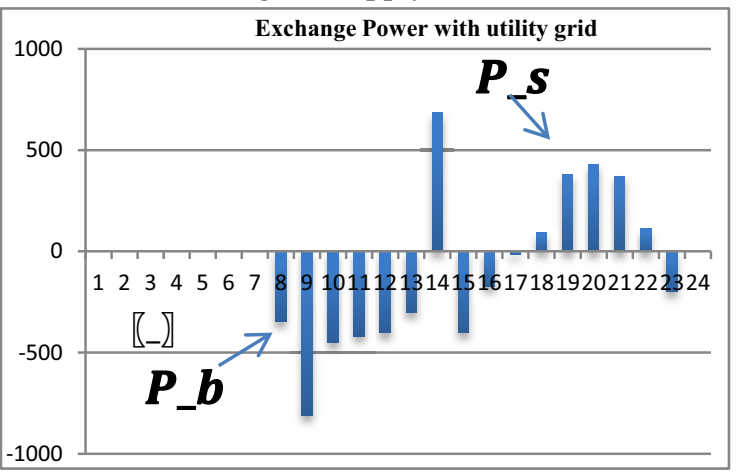

Fig. 7. Exchange power with utility grid.

Concerning the battery, the scheduled power profile and the charging/discharging of the battery during the day are presented in Figs. 8 and 9. As can be seen, the battery is discharged when the power stored from the RES is low while it is charged when there is high power in the RES.

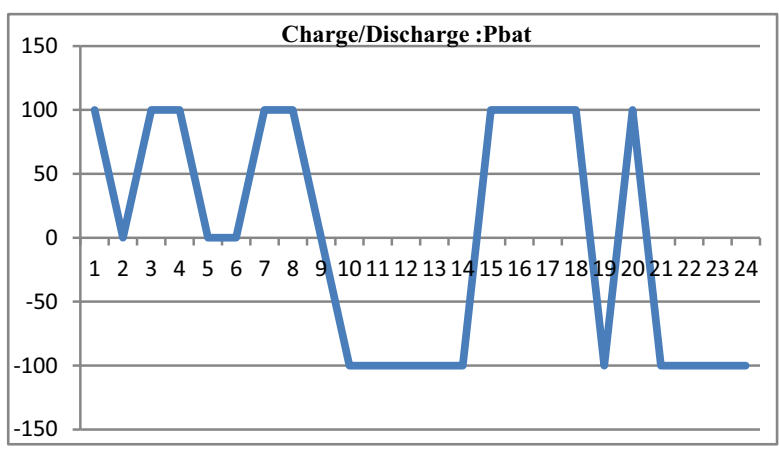

Fig.8. Charging/Discharging of battery during the day (24h).

The charging/discharging of the battery for the working day is presented in Fig8. The energy stored in the battery varies at different hours of the day.

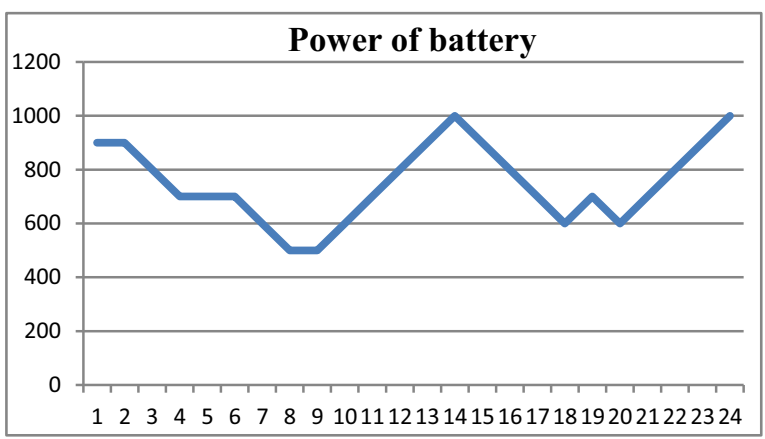

Fig.9. Power of battery during the day (24h).

As can be seen, in Fig.9, the scheduling keeps charging the battery to use the energy at the end of the day when the WT and PV do not generate energy.

Table 2. Parameter of the Model

\begin{tabular}{|c|c|}
\hline Name & Description \\
\hline $\mathrm{T}$ & Time scheduling \\
\hline i & Index of units of Res \\
\hline$C_{\text {sell }}^{\text {grid }}$ & Cost of selling energy \\
\hline$C_{\text {buy }}^{\text {grid }}$ & Cost of buying energy \\
\hline$P_{\text {res }}$ & $\begin{array}{l}\text { Power from renewables } \\
\text { Power from the utility }\end{array}$ \\
\hline$P_{\text {grid }}$ & Power bought from the utility \\
\hline$P_{\text {buy }}^{\text {grid }}$ & Power sold to the utility \\
\hline$P_{\text {sell }}^{\text {grid }}$ & Power of the battery \\
\hline$P^{b a t}$ & Maximum battery energy level \\
\hline$E S_{\max }^{\text {bat }}$ & Minimum battery energy level \\
\hline$E S_{\min }^{b a t}$ & Battery charging efficiency \\
\hline$\eta^{b a t, c h}$ & $\begin{array}{l}\text { Battery discharging efficiency } \\
\text { Binary variable }\end{array}$ \\
\hline$\eta^{\text {bat,disch }}$ & \\
\hline$\lambda_{\text {grid }}(t), B_{t}$ & \\
\hline
\end{tabular}


Table 3. Parameter of the Battery

\begin{tabular}{|c|c|c|l|c|}
\hline $\begin{array}{l}\text { Battery } \\
\text { unit }\end{array}$ & Energy $_{\min }$ & Energy $_{\max }$ & $P_{\max }$ charge & $P_{\max }$ Dischan \\
\hline 1 & 100 & 1000 & 100 & 100 \\
\hline
\end{tabular}

\section{Conclusion}

A mixed integer linear programming model has been used for a grid-connected hybrid PV-Wind- ESS microgrid system in order to minimize cost of buying energy from the grid and maximize profits for selling energy generated by RESs. The optimization strategy has been used to set optimal power references for the distributed resources of the microgrid. The simulation results confirm that the proposed strategy of EMS is effective in grid-connected hybrid PV-Wind- ESS. Future work includes implementing the proposed EMS in a real system, power losses and analyzing its performance and their influence.

\section{References}

1. Q. Jiang, M. Xue, and G. Geng, "Energy management of microgrid in grid-connected and stand-alone modes," IEEE Transactions on Power Systems, vol. 28, no. 3, pp. 3380-3389, Aug 2013.

2. M. Iqbal, M. Azam, M. Naeem, A. Khwaja, and A. Anpalagan, "Optimization classification, algorithms and tools for renewable energy: A review," Renewable and Sustainable Energy Reviews, vol. 39, no. 0, pp. $640-654,2014$.

3. J. de Matos, F. S.F.e Silva, and L. de S Ribeiro, "Power control in ac isolated microgrids with renewable energy sources and energy storage systems," IEEE Transactions

4. S. Pourmousavi, M. Nehrir, C. Colson, and C. Wang, "Real-time energymanagement of a stand-alone hybrid wind-microturbine energy system using particle swarm optimization," IEEE Trans. Sustain. Energy, vol. 1, no. 3, pp. 193-201, Oct. 2010.
5. P. Siano, C. Cecati, H. Yu, and J. Kolbusz, "Real time operation of smart grids via FCN networks and optimal power flow," IEEE Trans. Ind. Informat., vol. 8, no. 4, pp. 944-952, Nov. 2012.

6. S. Choi, S. Park, D.-J. Kang, S.-J. Han, and H.-M. Kim, "A microgrid energy management system for inducing optimal demand response," in Proc. IEEE Int. Conf. Smart Grid Commun. (SmartGridComm), Brussels, Belgium, Oct. 2011, pp. 19-24.

7. C. Cecati, C. Citro, and P. Siano, "Combined operations of renewable energy systems and responsive demand in a smart grid," IEEE Trans. Sustain. Energy, vol. 2, no. 4, pp. 468-476, Oct. 2011.

8. F. Katiraei, R. Iravani, N. Hatziargyriou, and A. Dimeas, "Microgrids management," Power and Energy Magazine, IEEE, vol. 6, no. 3, pp.54-65, May 2008.

9. S. C. C. 21, "Guide for optimizing the performance and life of leadacid batteries in remote hybrid power systems," IEEE Std 1561-2007, pp. C1-25, 2008.

10. F. Marra and G. Yang, "Decentralized energy storage in residential feeders with photovoltaics," in Energy Storage for Smart Grids, P. D.Lu, Ed. Boston: Academic Press, 2015, pp. 277 - 294.

11. R. Huang, T. Huang, R. Gadh, and N. Li, "Solar generation prediction using the ARMA model in a laboratory-level micro-grid," in Proc. IEEE Int. Conf. Smart Grid Commun. (SmartGridComm), Tainan, Taiwan, Nov. 2012, pp. 528-533.

12. I. El Kafazi, R. Bannari, A. Abouabdellah, My O. ABOUTAFAIL and Josep M. Guerrero. Modeling and Forecasting Energy Demand.5th International Renewable and Sustainable Energy Conference (IRSEC'17December 04-07, 2017). (ACCEPTED).

13. G. Sideratos and N. Hatziargyriou, "An advanced statistical method for wind power forecasting," IEEE Trans. Power Syst., vol. 22, no. 1, pp. 258265, Feb. 2007.

14. http://www.ges-lyon.fr 